\title{
FORMA DE VIDA FEMININA NA REVISTA VOCÊ S/A: UMA ANÁLISE SEMIÓTICA DO PERCURSO DE EMPODERAMENTO DO ATOR MULHER EXECUTIVA CONTEMPORANÊA
}

\section{FEMININE FORM OF LIFE IN VOCÊ S/A MAGAZINE: A SEMIOTIC ANALYSIS OF THE CONTEMPORARY EXECUTIVE WOMAN PATH OF EMPOWERMENT}

\author{
Raíssa Medici de Oliveira \\ Doutoranda em Linguística e Língua Portuguesa pela Universidade Estadual Paulista - Câmpus de Araraquara \\ Bolsista FAPESP \\ E-mail: raissamedici@yahoo.com.br
}

\author{
Edna Maria Fernandes dos Santos Nascimento \\ Livre-docente pela Universidade Estadual Paulista - Câmpus de Araraquara \\ Docente da Universidade Estadual Paulista - Câmpus de Araraquara \\ Bolsa de produtividade em pesquisa do $\mathrm{CNPq}$ \\ E-mail: edna.fernandes@uol.com.br
}

\section{RESUMO}

A presente pesquisa busca, com base no aparato teórico-metodológico da semiótica francesa, principalmente nos recentes estudos acerca das "formas de vida", conceito que tem motivado uma ampliação da noção de "ator", compreender o percurso de empoderamento do ator mulher executiva contemporânea dentro do cenário corporativo brasileiro. Para tanto, três matérias veiculadas na revista VOCÊ S/A foram selecionadas: "Mulheres no poder", "Garotas Superpoderosas" e "As rainhas da Ambev". Nossa hipótese inicial, confirmada ao final das análises, mostra que papéis e comportamentos tradicionalmente femininos são reiteradamente valorizados pelo enunciador do periódico, motivando o enunciatário a adotar um modo de fazer, ser, sentir e viver que, em princípio arrojado e de caráter unidimensional, revela-se, de fato, equilibrado, marcado por um estilo pluridimensional de vida. Assim sendo, a forma de vida feminina configurada acaba por revelar um ator capaz de galgar os mais altos escalões no espaço corporativo sem perder a elegância, a sensibilidade, a afetividade e a generosidade, em outras palavras, sem deixar de ser a feminina, doce e maternal mulher. Isso nos permite concluir que o percurso de empoderamento do ator mulher executiva contemporânea ainda está marcado por grandes e silenciosas permanências que, embora possam enfraquecer a constituição da identidade da mulher contemporânea, parecem, para o enunciador do periódico, fortalecer a figura mítica da executiva "poderosa", que concilia papéis, comportamentos e estilos de liderança diversos.

Palavras-chave: Semiótica francesa. Forma de vida. Mulher executiva contemporânea. VOCÊ S/A 


\section{ABSTRACT}

Based on the theoretical and methodological apparatus of French semiotics, mainly on the recent studies concerning the "forms of life", a concept which has motivated the expansion of the notion of "actor", this research aims at understanding the contemporary executive woman path of empowerment within the Brazilian corporate scenario. Therefore, three texts published in VOCÊ S/A magazine were selected: "Mulheres no poder", "Garotas superpoderosas" and "As rainhas da Ambev". Our initial hypothesis, which was confirmed at the end of the analysis, shows that traditional female roles and behaviors are repeatedly valued by the enunciator of the magazine. Such valorization motivates the enunciate to adopt a way of doing, being, feeling and living that, at first, is bold and marked by a one-dimensional aspect. Actually, it reveals itself as a balanced and multidimensional way of life. As a result, the feminine form of life depicted in the magazine reveals an actor capable of reaching the highest levels within the corporate scenario without losing the elegance, the sensibility, the affection and the generosity. In other words, without leaving behind the feminine, sweet and maternal woman. This leads us to conclude that the contemporary executive woman path of empowerment is still marked by big and silent stays which, although may weaken the constitution of the contemporary woman identity, they seem, to the enunciator of the magazine, to strengthen the mythical figure of the "powerful" executive, who conciliates different roles, behaviors and leadership styles.

Keywords: French semiotics. Form of life. Contemporary executive woman. VOCÊ S/A.

\section{INTRODUÇÃO}

Após a longa trajetória de lutas femininas empreendidas no espaço público, surge uma nova cultura do trabalho. É por meio dela que as mulheres buscam conquistar uma identidade profissional plena, baseada no talento e no mérito: “[...] a cultura competitiva do desafio e da estratégia de carreira fez estreia no universo feminino. Ser bem-sucedida nas organizações, visar aos postos de responsabilidade tornou-se um objetivo feminino midiatizado e socialmente legítimo" (LIPOVETSKY, 2007, p. 264). No entanto, a presença das mulheres no topo da pirâmide continua marginal, refletindo as barreiras conscientes e inconscientes que ainda precisam ser quebradas tanto pelos homens quanto pelas próprias mulheres:

[...] se o lugar das mulheres nos postos de nível superior deve depender ainda por muito tempo das barreiras conscientes ou inconscientes erguidas pelos homens, ele será cada vez mais função das motivações e dos gostos, das arbitragens e escolhas de vida das próprias mulheres (LIPOVETSKY, 2007, p. 274-275). 
Nesse sentido, pertence a nosso imaginário cultural a ideia de que os homens valorizam mais que as mulheres os salários elevados, os objetivos de carreira a longo prazo, as possibilidades de avanço e que, em contrapartida, elas privilegiam mais um trabalho rico no plano do conteúdo, a qualidade de vida no trabalho, o ambiente, as relações interpessoais. Assim, parece que a busca do poder pelo poder não é o que anima a maioria das mulheres líderes, embora isso não signifique que elas não tenham ambição: "mesmo não sendo ignorada, a vontade de poder é privada de sentido forte, associada que está a um estilo de vida unidimensional, dominador, sem laço emocional" (LIPOVETSKY, 2007, p. 296).

Partindo dessas reflexões iniciais, nosso objetivo é compreender como se constrói o percurso de empoderamento ${ }^{1}$ do ator mulher executiva contemporânea dentro do cenário corporativo brasileiro. Para tanto, selecionou-se uma revista de gestão de carreiras destinada a um público misto, de ampla faixa etária: VOCÊ S/A. Lançada pela Editora Abril em 1998, VOCÊ S/A veio ao mundo exibindo um projeto gráfico e editorial moderno, com textos curtos e de fácil leitura e dose elevada de informação visual. Além disso, chamou nossa atenção também o fato de o periódico ser produzido por uma equipe predominantemente feminina e o fato de metade de seu público ser composto por mulheres, embora o periódico nunca tenha apresentado uma seção que fosse exclusivamente dedicada a elas.

Para a consecução do nosso objetivo, foram recortadas as matérias "Mulheres no poder" (edição 47, maio de 2002), "Garotas superpoderosas" (edição 130, abril de 2009) e "Rainhas da Ambev" (edição 152, fevereiro de 2011). A justificativa para o recorte se fundamenta no fato de os três textos serem os mais representativos, ao longo de um período de mais de dez anos de publicação, para um estudo da associação entre as figuras /mulher/ e /poder/. A análise dos textos será conduzida a partir do referencial teórico-metodológico da semiótica francesa, conciliando a abordagem clássica da semiótica narrativa e discursiva com os recentes desenvolvimentos no âmbito das formas de vida, conceito proposto por Algirdas Julien Greimas (1993), a partir de Ludwig Wittgenstein (1999 [1953]), e retomado nos últimos anos por vários semioticistas.

\section{OS CONCEITOS DE “ATOR" E "FORMA DE VIDA"}

Lugar de convergência e de investimento dos componentes sintático e semântico, o "ator" é definido como a reunião de pelo menos um papel actancial e um papel temático (Greimas; Courtés, 2013, p. 45). Aquele se define em função da posição do actante no percurso narrativo e, ao mesmo tempo, do investimento modal particular que assume (Greimas; Courtés, 2013, p. 20). O 
actante-sujeito, por exemplo, poderá assumir os papéis actanciais de sujeito do querer, sujeito do saber, sujeito do poder-fazer, os quais definem sua competência modal (preliminar à performance). Já o papel temático se define por uma dupla redução: redução de uma configuração discursiva a um único percurso figurativo; redução desse percurso a um agente competente que o subsume virtualmente (Greimas; Courtés, 2013, p. 496). Trata-se de um modelo organizado de comportamento, ligado a uma posição determinada na sociedade, cujas manifestações são amplamente previsíveis, como o papel de "mãe", por exemplo. Esses papéis dotam o ator de um modus operandi e de um modus essendi, determinando, portanto, sua competência e os limites de seu fazer e ser.

Pertencente à semiótica clássica, cujo "percurso gerativo do sentido" constitui o principal aparato metodológico para a abordagem da construção da significação nos mais diversos textos, a noção de "ator" pode ser ampliada, no entanto, a partir do momento em que se considerem os recentes desdobramentos no âmbito das "formas de vida". É o que afirma Pierluigi Basso-Fossali (2012, p. 1, tradução livre nossa):

\begin{abstract}
A noção de forma de vida é bem-vinda e salutar na tradição semiótica porque ela parece repercutir um certo número de conceitos clássicos, promovendo um avanço teórico homogêneo e sistemático. Por exemplo, ela parece motivar a redefinição da noção de ator, instância semiótica à qual se atribui uma forma de vida; o ator seria então uma constelação temática de traços figurativos que tornam compatíveis papéis actanciais diversos e que constituem, ao mesmo tempo, uma reserva de possibilidades identitárias ainda não atualizadas pela trajetória existencial em curso (a forma de vida como potencial narrativo salvaguarda o ator das frustrações e lhe atribui um reservatório de chances existenciais inexprimidas).
\end{abstract}

Introduzido na semiótica francesa a partir do último seminário de Greimas na École des Hautes Études em Sciences Sociales [E.H.E.S.S.], o conceito de "forma de vida", tomado emprestado a Wittgenstein (1999 [1953]), teve suas primeiras sistematizações registradas no dossiê "Les formes de vie", organizado por Jacques Fontanille (1993) e publicado na revista canadense Recherches Sémiotiques. Semiotic Inquiry [R.S.S.I.]. Já era claro para os semioticistas, naquele momento, a amplitude do projeto que se delineava: com o estudo das formas de vida, poder-se-ia conceber a organização da sociedade a partir da complexidade moral dos seres semióticos que a constituem e não somente por meio das suas composições institucionais ou distribuições topológicas (Greimas, 1993, p. 32-33).

Compreendidas como gestão da própria identidade face à figura complementar do outro (Landowski, 1993, p, 69), as formas de vida têm como fundamento principal um estado de alma, visto como sintoma de uma intencionalidade específica ligada à própria forma de vida (Fontanille, 1993, p. 11). Assim sendo, a semiótica passa a buscar as variedades de formas de vida geradas 
pelos vários estados de alma do sujeito (provocados pela interação, no seu cotidiano, com o outro, seja ele um sujeito ou um objeto) e a narratividade, por conseguinte, passa a ser compreendida não mais como um modelo lógico de busca do objeto, mas como um simulacro das práticas humanas que regem a ação, o saber e o sentir do sujeito no seu percurso pelo mundo (Nascimento, 2011, p. 124-125).

Desse modo, a forma de vida está aliada a um comportamento esquematizado profundo que representa não somente o estilo individual, mas uma filosofia de vida de um determinado grupo cuja ruptura provoca uma mudança radical de forma de vida (Greimas, 1993, p. 32-33). A esse respeito, Fontanille (2015, p. 78) explica que uma forma de vida existente é virtualizada no momento em que o sujeito rompe com as normas, usos e costumes estabelecidos e passa a se inscrever na perspectiva de uma nova "ideologia", de uma nova "concepção de vida", atualizando uma forma de vida nova. Segundo ele, a realização dessa forma de vida será coletiva ou, ao menos, passará pelo crivo da coletividade.

As formas de vida são, portanto, "linguagens" que, uma vez assumidas por atores individuais ou coletivos, podem dar uma resposta à questão da constituição das identidades nos discursos, segundo Jean Cristtus Portela e Matheus Nogueira Schwartzmann (2012, p. 120-121):

\begin{abstract}
Entendemos a forma de vida como uma macroisotopia temática e figurativa, urdida na cultura e inscrita na enunciação, que orienta a produção de percursos narrativos, temáticos e figurativos que definem identidades nos discursos, sejam identidades de atores individuais, singulares, sejam identidades de atores coletivos. No caso de a identidade ser individual, conduta encarnada em um sujeito determinado, não podemos perder de vista que tal conduta só é apreensível enquanto totalidade à luz da coletividade, como ideologia que se faz a partir de uma axiologia, ambos os termos aqui compreendidos no sentido que têm no Dicionário de semiótica (GREIMAS; COUTÉS, 2008). No caso de identidades coletivas, cujo caráter também é axiológico, é curioso notar o ir e vir entre a identidade coletiva e suas manifestações pontuais, que imprimem variações estilísticas importantes às formas de vida.
\end{abstract}

É essa investigação das diferentes formas de vida assumidas por diferentes atores, formas de vida configuradas em diferentes textos da cultura, que têm norteado o trabalho de muitos semioticistas brasileiros, como se constata ao longo dos artigos reunidos nas obras "Formas de vida da mulher brasileira" (2012) e "Formas de vida: rotina e acontecimento" (2014). Nesse sentido, seria possível dizer que o ator, dotado de um modus operandi e de um modus essendi, abarca também, ao assumir uma determinada forma de vida, um modus vivendi que define uma maneira característica de responder ao mundo que o rodeia e de conceber senão o "sentido da vida", ao menos o "sentido da sua vida", conforme expressões tomadas a Claude Zilberberg (1999). 


\section{O "PODER" COMO PAIXÃO OU ESTADO DE ALMA}

Recorrendo ao "Dicionário de Paixões Literárias" (2005, p. 266-278), constatamos, logo de início, que a paixão do poder é uma paixão "sem nome", pois não há um lexema, em qualquer língua que seja, que a delimite da forma como se faz com as paixões do querer (a ambição sendo uma delas), as paixões do crer (o fanatismo, por exemplo) ou as paixões do saber. Sabe-se, no entanto, que o homem é um ser dominado pela inquietude relativa à incerteza do porvir, e essa inquietude faz com que deseje exatamente aquilo que possa lhe assegurar um futuro satisfatório. Nesse sentido, parece que "somente o poder pode lhe dar essa certeza" (2005, p. 266).

Assim sendo, para que esse desejo coletivo de conquistar aquilo que garanta um futuro satisfatório se transforme numa paixão, é necessário que ocupe o homem de maneira exclusiva e excessiva, de modo que este seja capaz de colocar tudo em jogo a fim de conquistar o poder. Além disso, entra em jogo o julgamento do outro, que é essencial para o apaixonado pelo poder: “[...] ou bem ele é rejeitado, pois suas estratégias não são eficazes; ou bem ele ganha a adesão, e encontra-se então sob a via do triunfo" (2005, p. 268).

Desse modo, acredita-se que o homem de poder é um ser semiótico complexo, pois pode carregar em si diversas paixões, como a ambição ou o ódio, além do desejo de posse e de dominação, tensões que são da ordem do querer: quando se "quer" o poder, o objeto do poder está "distante" e é cobiçado justamente por estar fora do alcance do sujeito; em outras palavras, ele pertence a um espaço "utópico", ao espaço de um outro a quem o objeto deverá ser tomado (2005, p. 268). Trata-se de um tipo de paixão pelo poder que pode ser definida como "paixão da supremacia": ligada a uma forma de desejo que "queima a pequeno fogo" e que pode ser cotidiano e privado, essa paixão degenera frequentemente em paixão incontrolável, podendo ser levada a todos os excessos, num jogo perverso com o outro. O homem dominado por esse tipo de poder faz dos sujeitos aquilo que quer e, logo, os outros são transformados em imagens do seu querer: eles são vistos como capazes de lhe dar satisfação. É a paixão do perverso, que ambiciona reinar sobre suas vítimas, manipulá-las até que elas se prendam a ele. Ela é também a paixão do chefe.

Parece haver, no entanto, outra forma de paixão pelo poder, embora o verbete não chegue a explorá-la: em relação à passion de l'emprise (que traduzimos "paixão da supremacia"), menciona-se a passion du pouvoir public (que traduzimos “paixão do poder público"). Esta paixão camufla a libido dominandi, uma vez que se exerce na esfera pública, como desejo de fazer o bem ao maior número de pessoas possível (2005, p. 267). Uma vez que o texto não explora com profundidade esse segundo tipo paixão pelo poder, recorremos a Eric Landowski (2002, p. 190), que, ao tratar das formas de popularidade, nos permite compreender melhor o que "move" o sujeito dominado por esse desejo de "fazer o bem" aos seus subordinados/subalternos: 
Para ter sucesso, para fazer um "nome", é preciso evidentemente em primeiro lugar chegar ao menos a se fazer conhecer, nem mais nem menos como se dá a conhecer a uma clientela potencial a existência de um novo produto no mercado: é a notoriedade. Mas, em seguida, para se tornar realmente o que, com razão ou não, se chama um "grande" ator, um escritor "importante", uma personalidade "que conta", é preciso também, sobretudo, deixar-se conhecer, saber abrir-se suficientemente para dar a cada um o sentimento de que o "conhece" [...]. Mostrar-se aberto a todos, apresentar-se para o maior número possível sem a máscara profissional, deixar-se perceber em sua verdadeira identidade ou pelo menos dar a impressão disso: assim se cultiva, além de notoriedade, uma forma de adesão fundada no sentimento de uma familiaridade interindividual, se possível matizada de "simpatia".

Acreditando que é esse desejo de "notoriedade" que está no cerne da "paixão do poder público", uma vez que a qualidade das relações interpessoais e os laços emocionais parecem ter primazia sobre qualquer tipo de resultado ou ganho material, passamos à investigação do nosso objeto de pesquisa.

\section{O PERCURSO DE EMPODERAMENTO FEMININO EM VOCÊ S/A}

\subsection{MULHERES NO PODER}

Ocupando a extensão das páginas de abertura da matéria, o título "Mulheres no poder", impresso em caixa alta e traçado grosso numa fonte tipográfica sem serifa ${ }^{2}$, traz peso e presença aos olhos, homologando, assim, os sememas que compõem a figura lexemática/poder/: "autoridade", "domínio", "potência", "supremacia” (Houaiss; Villar, 2001). Formando sintagma com /poder/, a figura /mulher/ define um ator identificado ao longo do texto por meio do papel actancial de sujeito do /querer/ e do /poder/ e dos papéis temáticos de /executiva/, /mãe/ e /esposa/. Ligadas por uma preposição de lugar, as figuras definem uma "posição" que, apesar de culturalmente marcada por traços de austeridade/rigidez, ganha, ao se associar à figura feminina, traços de maleabilidade: "Cinco executivas muito bem-sucedidas dão uma aula de jogo de cintura e contam o que fazem para conciliar a vida dentro e fora de casa" (ROCHA, $V O C \hat{E} S / A$, edição 47, 2002, p. 38, grifos nossos).

Ao longo dessas páginas, há um texto-imagético (ver Figura 1) que constrói de maneira conjunta o simulacro dessas mulheres. Com exceção do vermelho empregado no título e em uma das indumentárias, predominam tons sóbrios que ajudam a configurar esses atores em um espaço interno que simula uma sala de uma grande empresa/escritório: três desses atores são figurativizados em primeiro plano, em posição sentada, sobre grandes e largas poltronas, as quais reiteram o efeito de sentido de grandiosidade, potência; todos três têm as pernas cruzadas e apresentam as mãos apoiadas sobre o corpo. Em segundo plano, estão outros dois atores que, em 
posição vertical, apoiam as mãos sobre o espaldar das referidas poltronas. Todos os cinco atores são figurativizados com o rosto levemente inclinado, sorriso estampado na face e olhar direcionado para um lugar não identificado:

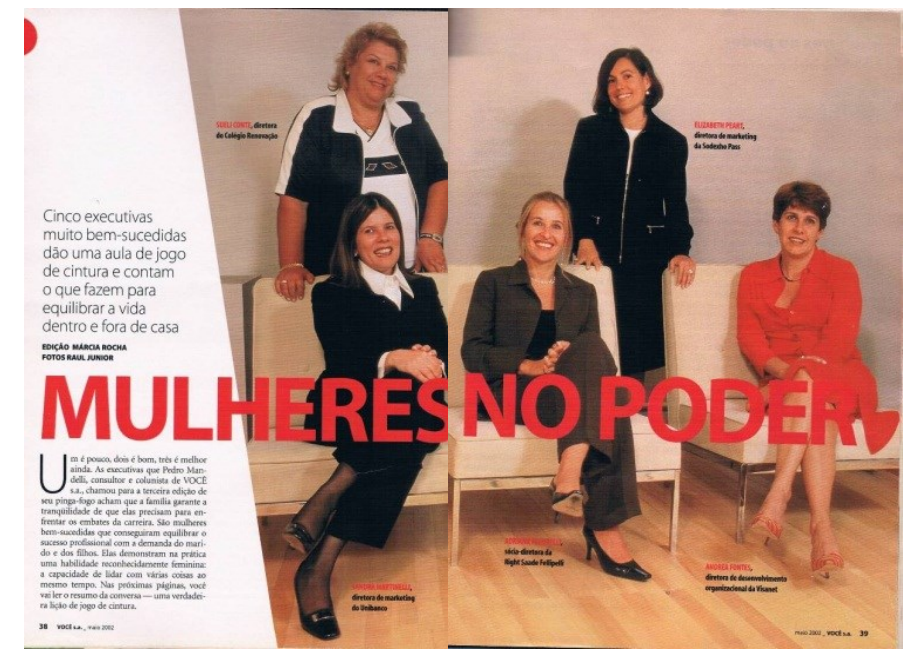

Figura 1 - Abertura da matéria "Mulheres no poder"

Todo esse conjunto de elementos cria um jogo interessante de efeitos de sentido que se alternam entre austeridade/rigidez e maleabilidade. A esse respeito, é interessante destacar o que Chico Buarque e Paulo Pontes (1976), resgatando nosso imaginário cultural, registram na peça "Gota d'água", num diálogo entre os personagens Creonte e Jasão. Sobre a poltrona/cadeira, Creonte afirma que ela molda o homem, pois existe algum mistério no sentar que faz com que o homem, mesmo rindo, fique sério. A cadeira, segundo essa personagem, é parte da vida de todos os tipos de pessoas, principalmente das com muita influência e poder. Sobre o modo de sentar e o posicionamento do corpo e do olhar, bem como o posicionamento dos pés calçados, revelando a sola dos sapatos ao interlocutor ${ }^{3}$, Creonte ensina Jasão:

Ergue a cabeça, estufa o peito, fica olhando a linha de fundo, como que a olhar nenhum lugar. Seguramente é o melhor jeito que há de se olhar pra todo mundo sem ninguém olhar teu olhar. Mostra total descontração, deixa os braços soltos no ar e o lombo sempre recostado. Assim é fácil dizer não, pois ninguém vai imaginar que foi um não premeditado. Cruza as pernas que o teu parceiro vai se sentir mais impotente vendo a sola do teu sapato. E se ele ousar falar primeiro descruza as pernas de repente que ele vai entender no ato (1976, p. 35, grifos nossos) (BUARQUE; PONTES, 1976, p. $35)$.

Dando prosseguimento à análise da matéria, observa-se um texto organizado em sessões de perguntas e respostas; ao final de cada uma, o enunciador elabora um comentário que funciona como uma espécie de "conselho ao enunciatário". Desses enunciados-conselhos, depreende-se um enunciador que ressalta a importância dos papéis temáticos de /mãe/ e /esposa/ na configuração do 
ator mulher executiva contemporânea. Ao questionar, por exemplo, se os atores consideram que teriam mais sucesso profissional se fossem sozinhos, o enunciador revela que o apoio da figura /marido/ é essencial: algumas das entrevistadas afirmam que não conseguiriam ser o que são se não tivessem o apoio do marido, pois se sentiriam inseguras; outras afirmam que conseguiriam, mas que seria muito mais complicado, pois o relacionamento estável traz tranquilidade, algo fundamental pra o trabalho. Concluindo que “A dois é melhor”, o enunciador declara:

Interessante é que a resposta de vocês é a mesma que os homens davam no tempo em que
as esposas ficavam em casa. Isso me leva a concluir que, ao alcançar uma posição
executiva, o homem e a mulher acabam concordando no que diz respeito a valores,
casamento e relacionamento com a família (ROCHA, VOCE $S / A$, edição 47, 2002, p. 40).

Logo nesse primeiro enunciado-conselho, vê-se que o enunciador tenta convencer o enunciatário sobre a importância da /família/ na consolidação da carreira da mulher executiva; para isso, argumenta que é assim que todos os profissionais em posição executiva, homens e mulheres, pensam e agem. Há, nesse sentido, certo efeito de padronização do comportamento desses atores: a mulher executiva precisa ter o foco no trabalho, na carreira; para tanto, a família pode agir como uma espécie de "mola propulsora" capaz de levá-la a conquistar a realização profissional com muito mais tranquilidade e segurança - tal como sempre ocorreu com os homens, faz-crer o enunciador.

Esse efeito de padronização do comportamento executivo é reiterado outras vezes, como se observa na segunda pergunta: após indagar as executivas como elas lidam com o machismo nas empresas, o enunciador destaca: "Acerte o foco"; em seguida, elabora um enunciado que reitera seu ponto de vista e faz-crer que homens e mulheres em posição executiva devem não apenas pensar, mas também agir da mesma forma, focando sua atenção nos resultados, no desenvolvimento pessoal e na utilização de competências, ou seja, "assuntos que dizem respeito a qualquer profissional, independentemente do sexo" (ROCHA, VOCE $S / A$, edição 47, 2002, p. 41).

$\mathrm{Na}$ terceira seção de perguntas, o entrevistador indaga se as executivas tentam gerenciar a vida e a carreira do marido, já que, segundo ele, os homens sempre fizeram isso com as esposas. A própria formulação da pergunta dá indícios de um posicionamento favorável à padronização de homens e mulheres em posição executiva. Nesse sentido, uma das entrevistadas destaca a necessidade de trazer o modo de se relacionar na empresa para o relacionamento a dois; outra entrevistada, seguindo a mesma linha de pensamento, fala sobre a necessidade de manter certa cerimônia no relacionamento a dois: "[...] quando ele vier com aquele papo chato - e, às vezes, eles vêm mesmo -, você deve pensar: se ele me falasse isso quando a gente namorava, eu daria atenção" (ROCHA, VOCE S/A, edição 47, 2002, p. 41). Ao final das respostas, o enunciador declara: "Faça cerimônia"; em seguida, ensina que: 
Na organização, é preciso buscar e manter certa cerimônia com os colegas. Geralmente, as pessoas adotam esse comportamento nas relações profissionais porque costumam cuidar mais do que é menos duradouro. Mas é preciso preservar a estética em todas as relações, inclusive na vida a dois (ROCHA, $V O C \hat{E} S / A$, edição 47, 2002, p. 41-42).

Por meio desse enunciado-conselho, compreendemos que o enunciador se posiciona a favor não apenas da padronização do comportamento de homens e mulheres em posição executiva, mas também a favor da padronização de um tipo de comportamento ("cerimonioso") tanto para as relações profissionais mantidas no espaço da empresa quanto para as relações pessoais mantidas no espaço doméstico. Desse modo, ao fazer uso do lexema /estética/ o enunciador revela-se preocupado não apenas com ações e resultados, mas com a manutenção de um significado maior construído nas/pelas relações com o outro.

Novas perguntas e novos enunciados-conselhos aparecem, sempre buscando a preservação dos laços familiares, como apontam os títulos que encabeçam esses enunciados: “A dois é melhor", "Acerte o foco", "Faça cerimônia", "Admire o parceiro". No final da matéria, o enunciador assevera de modo contundente e levemente irônico: "Seja egoísta. Notaram que as respostas estão centradas em vocês mesmas? O parceiro e a empresa são transitórios. Por isso, é preciso exercer um egoísmo saudável” (ROCHA, VOCÊ $S / A$, edição 47, 2002, p. 43). Desse enunciado, depreende-se a necessidade de equilíbrio para que essas mulheres não ultrapassem os limites do que é "saudável" ou, ainda, socialmente "aceitável” para o comportamento de uma mulher.

Entra então em jogo a questão do poder. Mais que por um poder supremo, essas mulheres são convocadas a exercerem um tipo de poder mais ameno: dentro do espaço doméstico elas devem mascarar/disfarçar seus traços de autoridade, mostrando-se agradáveis, delicadas, brandas no modo de relacionar-se com o parceiro; devem também revelar um egoísmo que está sempre dentro dos limites do que é saudável, ou seja, mostrar que não pensam somente nelas mesmas e em suas carreiras: a família e a empresa também são importantes para sua realização pessoal. Está explicitamente colocada pelo enunciador da matéria, portanto, a necessidade de rompimento do vínculo entre a ideia de sucesso profissional e perda da feminilidade, rompimento com o estereótipo de adoção de um comportamento austero/rígido, desprovido de "jogo de cintura" e "sensibilidade". O mito da executiva "andrógina" parece, por fim, estar sendo desmistificado pelo enunciador de $V O C \hat{E} S / A$. Veremos se isso procede nas outras reportagens selecionadas.

\subsection{GAROTAS SUPERPODEROSAS}

O título "Garotas superpoderosas" chama atenção pela relação que mantém com o título da primeira matéria. Em ambos, o lexema /poder/ está relacionado à figura feminina, embora o 
lexema empregado para particularizar essa figura seja distinto. A esse respeito, a presença de um prefixo e de um sufixo - formando a figura lexemática /superpoderosas/ - faz com que a escolha da figura /garotas/ adquira novo sentido. A junção dos lexemas /garotas/ e /superpoderosas/, formando sintagma, remete-nos a uma série de desenho animado americano que, no Brasil, é conhecida como "As garotas superpoderosas". O desenho tem por personagens principais três garotinhas que, dotadas de superpoderes, combinam inteligência, beleza, sensibilidade e força na luta contra o mal. Parece que a combinação é perfeita para as executivas cujo simulacro é construído nas páginas dessa reportagem, pois "Elas administram carteiras de até 90 milhões de reais e comandam equipes formadas quase que somente por homens" (VOCÊ $S / A$, edição 130, 2009, p. 82) ${ }^{4}$.

Considerando, por ora, o texto-imagético (ver Figura 2) construído ao longo das primeiras páginas, depreendemos o simulacro de três mulheres. Configurados em um espaço interno, que também simula uma sala de empresa/escritório, os atores são figurativizados por meio de uma postura autoritária, que conota austeridade/rigidez: olhar fixo em um ponto que remete ao lugar ocupado pelo enunciatário, corpo marcado por um posicionamento vertical levemente reclinado para a dianteira, mãos espalmadas firmemente sobre uma larga mesa de madeira. Essa última figura, construída de modo que pareça ao enunciatário que a mesa se estende em sua direção, mantém certa relação com as grandes e largas poltronas da matéria anterior, ambas as figuras remetendo a um espaço que é da ordem do grandioso, do majestoso, e que produz, dentre outros, o efeito de sentido de /poder/. Corrobora esse efeito o vestuário dos atores, que prima pela formalidade, sobriedade:

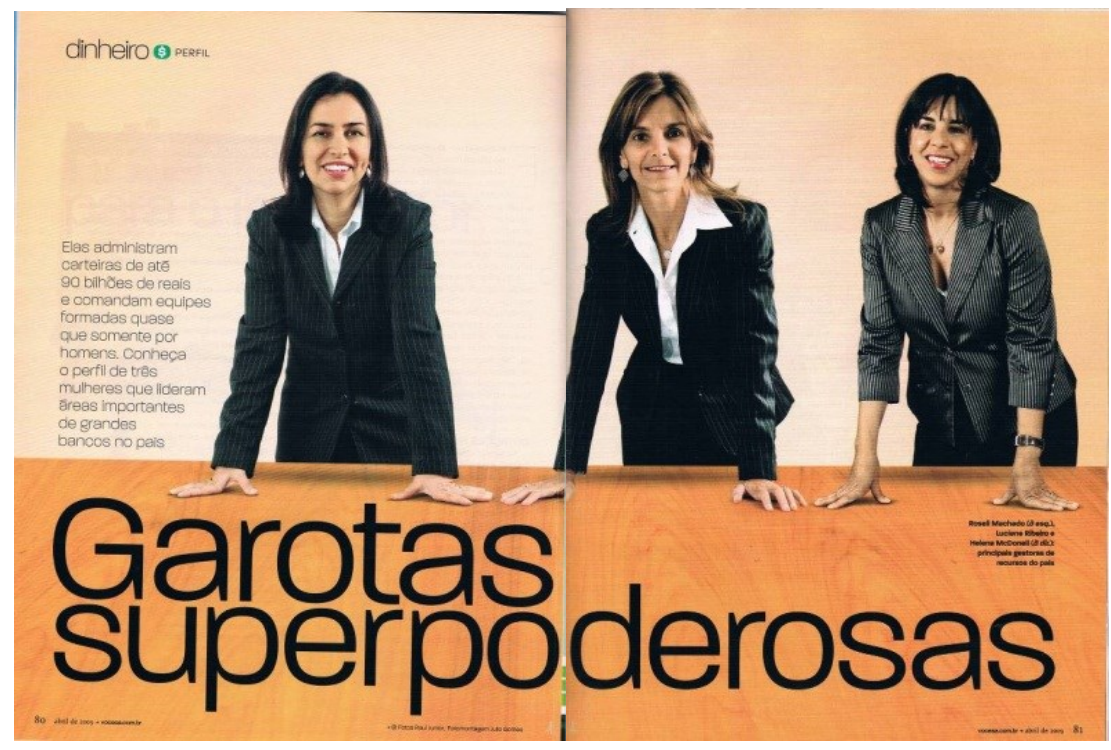

Figura 2 - Abertura da matéria "Garotas superpoderosas" 
Tal efeito de sentido, construído por aspectos da ordem da organização topológica do texto-enunciado, não deixa, entretanto, de criar um jogo interessante com o seu oposto, o efeito de maleabilidade: a figura/sorriso/ e a própria escolha do enunciador pelo emprego, no título da matéria, de uma fonte tipográfica da família Franklin Gothic ${ }^{5}$, bem como da caixa baixa e de um traçado mais fino, imprimem traços de leveza e humor à matéria e terminam por relativizar o modelo de executiva extremamente masculinizada de "outros tempos". É o que se comprova logo no primeiro enunciado da matéria, disposto na página seguinte:

Terno, fala agressiva e um estilo arrojado. Foi assim, adotando um perfil masculino, que até a década de 80 as mulheres conseguiam ocupar cargos no mercado financeiro. [...] "Se a mulher fosse muito feminina, ela não era aceita nas instituições", diz Carmen Migueles, professora de antropologia do consumo e cultura organizacional da Fundação Dom Cabral, em Minas Gerais. Hoje, o cenário é diferente (VOCÊ S/A, edição 130, 2009, p. $82)$.

Assim sendo, o enunciador descreve o ambiente de trabalho, a rotina profissional (e pessoal) dessas mulheres, separando cada perfil com um título específico. Dentro de cada uma dessas partes, apresenta também um pequeno quadro no qual há uma síntese da sua trajetória profissional. Há ainda três imagens fotográficas que figurativizam individualmente cada um dos atores apresentados conjuntamente nas páginas de abertura e, sobreposto a essas imagens, um pequeno quadro denominado "Perfil": nesse quadro, o enunciador elenca alguns pontos importantes do perfil das executivas. Sob o título "Competência reconhecida", o enunciador apresenta o ator Luciane Ribeiro, 45 anos, formada em economia pela Fundação Armando Álvares Penteado (Faap), e presidente da asset management do Grupo Santander Brasil:

\footnotetext{
A gestora faz parte de um seleto grupo de mulheres que ocupam cargos de confiança e que já sofreram preconceito no trabalho. "No início da carreira, em reuniões com homens, eu achava que ninguém me escutava. Eu tinha de falar alto, mas isso mudou quando provei minha capacidade", diz Luciane. Hoje, depois de 25 anos de carreira, ela foi a responsável por integrar as operações de asset e os profissionais da área do Banco Real e do Santander em meio à crise financeira internacional no ano passado. "Perdi noites de sono porque queria transmitir um voto de confiança para a equipe" (VOCE $S / A$, edição 130, 2009, p. 82).
}

Do texto-enunciado que apresenta o percurso narrativo do ator Luciane, depreende-se um querer-fazer e um querer-ser aquele que faz que contradizem os obstáculos a priori colocados por um não-poder-fazer e um não-poder-ser, bem como por um saber-não-ser. Interessante no enunciado é, ainda, o destaque dado para um modo de portar-se que muda ao longo do percurso: inicialmente, apreende-se um ator que, buscando equiparar-se à referência masculina, porta-se de 
uma maneira diferente, que não condiz com seu "eu"; em seguida, percebe-se que ele tem a permissão de voltar a ser quem "é": "eu tinha de falar alto, mas isso mudou quando provei minha capacidade" (VOCÊ $S / A$, edição 130, 2009, p. 82). Nesse percurso, o /poder/ manifesta-se por meio do reconhecimento conquistado a "duras penas":

Com o tempo, ela demonstrou suas habilidades e foi reconhecida pelos outros profissionais. "Chefe novo é sempre difícil, mas com dedicação e uma postura correta, ela conquistou a equipe", diz Aquiles Mosca, de 34 anos, superintendente comercial e estrategista de investimentos pessoais do Santander Asset, que trabalha com Luciane há três anos (VOCE $S / A$, edição 130, 2009, p. 82, grifos nossos).

Do enunciado, depreende-se uma narrativa na qual o mais importante, para o ator configurado, é conquistar a equipe e, consequentemente, ser reconhecido. Para chegar a isso, o apoio da família (como em "Mulheres no poder") é essencial, conforme garante um dos cinco pontos que o enunciador destaca no perfil de Luciane: "Quando chego em casa cansada e vejo o sorriso do meu filho, tenho a impressão que dormi e acordei de novo" (VOCÊ $S / A$, edição 130, 2009, p. 83).

A referência masculina, a busca por uma padronização do comportamento feminino pelo comportamento masculino - pelo menos num primeiro momento, conforme já destacamos - é também marcada na narrativa do segundo ator configurado: Roseli Machado, 44 anos, diretora da Fator Administração de Recursos, de São Paulo. Por meio de uma debreagem enunciva que instaura uma debreagem interna, o enunciatário conhece esse ator:

Ela administra 4 bilhões de reais e comanda 37 homens. Diante de tantos profissionais do sexo masculino, ela diz que o relacionamento da equipe dá supercerto. "Os homens são objetivos e eu sou objetiva também. Eles sabem rapidamente quais são os resultados que eu espero, diz” (VOCÊ S/A, edição 130, 2009, p. 83).

Desse enunciado, depreende-se um modo de agir marcado por um estereótipo masculino: a mulher é bem aceita se ela for como os homens são. No entanto, outros enunciados atuam no sentido de atenuar esse comportamento, ressaltando uma busca pelo equilíbrio entre características masculinas e características femininas. Assim, o enunciador dá voz a um profissional que conhece Roseli há 13 anos: “ela consegue compatibilizar a capacidade analítica com a sensibilidade e com isso antecipar as tendências do mercado". Segundo ele, a mulher tem, por natureza, um perfil mais conservador; não se arrisca tanto. Entretanto, "Roseli consegue equilibrar a hora certa de assumir riscos e a hora de colocar o pé no chão" (VOCE $S / A$, edição 130, 2009, p. 43). A padronização da figura feminina pela masculina no que tange ao modo de pensar e 
ao modo de portar-se deve não anular, portanto, algumas características marcadamente femininas, como garantem os enunciados apontados, todos eles organizados sob o título "Objetividade e sensibilidade".

O último perfil é apresentado sob o título "Equilíbrio e serenidade”: Helena McDonell, 53 anos, psicóloga com pós-graduação em marketing e finanças pela Fundação Getúlio Vargas (FGV), e diretora do HSBC Private Banking, de São Paulo, é, dos atores configurados, não somente o de mais idade, mas também o que destaca mais explicitamente os embates enfrentados no início da carreira, com os pares homens. Em seu percurso, o enunciador destaca a conciliação, o "equilíbrio" entre vida profissional e vida familiar:

Durante a semana, Helena organiza passeios e jantares com o filho e o marido. Para aliviar o estresse, ela prepara pratos da cozinha indiana, mergulha, anda a cavalo e cuida do jardim e da horta que tem na casa de praia. "Eu decidi que eu mesma cuidaria deles. Estou louca para voltar para lá para transplantar os temperos", diz ( $V O C \hat{E} S / A$, edição 130, 2009, p. 85).

Além disso, depreende-se, ainda, a possibilidade de uma aprendizagem mútua entre homens e mulheres, podendo aqueles vir a aprender com estas:

Gilberto Poso, de 40 anos, é diretor do Private HSBC para a região Centro-Norte e trabalha há quatro anos com a executiva [...]. 'Em uma reunião que tivemos, eu me posicionei de forma ríspida e ela disse para eu ter mais cuidado na hora de expor meus argumentos, mesmo que eles pareçam estar certos', diz Gilberto (VOCE $S / A$, edição 130, 2009, p. 85).

Depreendemos, pois, uma padronização que se dá apenas num primeiro momento; em seguida, resgata-se a identidade feminina por meio do postulado do equilíbrio entre características ou estilos masculinos e femininos de gestão. O enunciador destaca, ainda, a possibilidade de uma modificação positiva do ambiente corporativo a partir de um modo de ser feminino. Podemos antecipar que o percurso de empoderamento da mulher executiva contemporânea segue uma escala: em um primeiro momento, é preciso que essa mulher adote e/ou valorize o que é tido como estilo masculino e prove sua competência; em um segundo momento, que ela volte a assumir um modo de ser feminino e busque um equilíbrio entre os dois estilos de liderança e comportamento; por último, que ela passe a ser capaz de modificar positivamente não somente o ambiente corporativo, mas também os seus pares homens, dando-lhes possibilidades de serem menos austeros menos rígidos no trato com as pessoas. Parece que estamos, de fato, diante de um sujeito movido por um tipo de paixão do poder que não se traduz em termos de "supremacia", mas em termos de "notoriedade". 


\subsection{RAINHAS DA AMBEV}

Definida como "a soberana de um reino" (HOUAISS; VILLAR, 2001), a figura lexemática /rainha/ produz, ao ser empregada no título da terceira reportagem, o efeito de sentido de /poder/. Esse efeito se relaciona, consequentemente, ao lexema /Ambev/, o qual define a maior cervejaria da América Latina. As "rainhas" são, assim, aquelas que comandam soberanamente o "reino Ambev", configurado a partir do simulacro de cinco garrafas de cerveja gigantes, em cujos rótulos constrói-se o simulacro dessas mulheres (ver Figura 3):

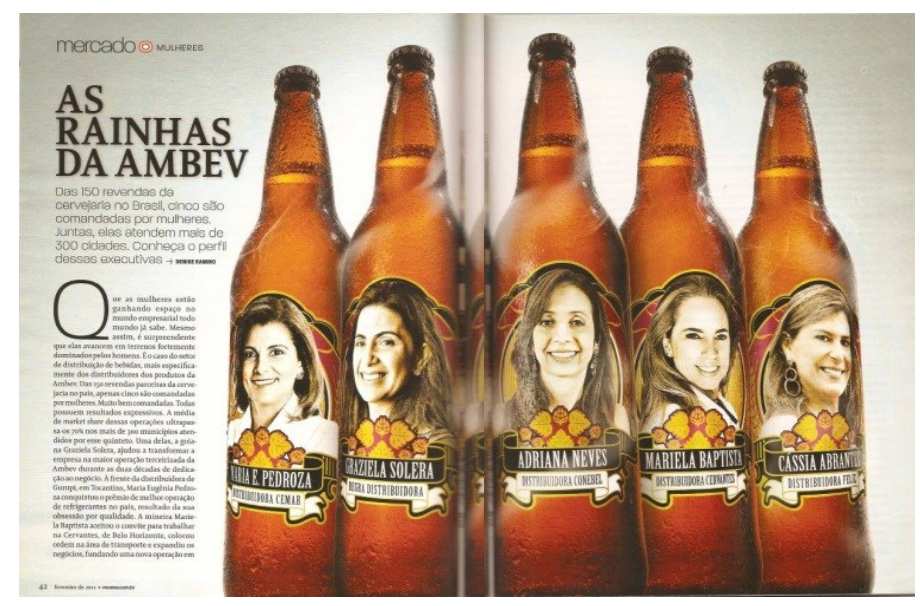

Figura 3 - Páginas de abertura da matéria "Rainhas da Ambev"

Maria E. Pedroza, Graziela Solera, Adriana Neves, Mariela Baptista e Cássia Abrantes são os cinco atores que, ao terem seus rostos estampados nos rótulos das cervejas (quando apenas corpos esculturais costumam ganhar esse espaço), quebram uma isotopia de leitura calcada na memória cultural do ocidente e reiteram o efeito de sentido de "autoridade", "potência", "supremacia" contidos no lexema /poder/. No entanto, a construção dessa presença feminina em um universo tipicamente masculino, austero e rígido - o ramo da cervejaria - é feita, contrariamente ao que se poderia esperar, com uma pitada de descontração: ao estampar a figura /sorriso/ no rosto desses atores e ao escolher uma fonte tipográfica com serifa para o título da matéria, o enunciador brinca com o contraste entre austeridade/rigidez e maleabilidade - mais uma vez.

Destacando a expecionalidade dessas mulheres que conquistaram seu espaço num universo tipicamente masculino, o enunciador inicia a matéria: "Das 150 revendas da cervejaria no país, apenas cinco são comandadas por mulheres. Muito bem comandadas. Todas possuem resultados expressivos. A média de market share dessas operações ultrapassa os $70 \%$ nos mais de 
300 municípios atendidos por esse quinteto" (RAMIRO, VOCE $S / A$, edição 152, 2011, p. 42). Continuando sua argumentação, o enunciador faz-crer que essas mulheres não apenas conquistaram seu espaço, mas se destacaram dentro dele de tal forma que se alçaram acima do lote comum:

\begin{abstract}
Uma delas, a goiana Graziela Soleira, ajudou a transformar a empresa na maior operação terceirizada da Ambev durante as duas décadas de dedicação aos negócios. À frente da distribuidora de Gurupi, em Tocantins, Maria Eugênia Pedroza conquistou o prêmio de melhor operação de refrigerantes no país, resultado de sua obsessão por qualidade. A mineira Mariela Baptista aceitou o convite para trabalhar na Cervantes, de Belo Horizonte, colocou ordem na área de transporte e expandiu os negócios, fundando uma nova operação em Montes Claros, região do Norte de Minas. Outra mineira, Cássia Abrantes, largou a carreira promissora na área bancária e assumiu a distribuição da cervejaria na Zona da Mata pernambunca, na cidade de Carpina. Hoje coleciona quatro prêmios de melhor operação no Nordeste. A paulista Adriana Neves chegou à Conebel, revenda de São José do Rio Preto, interior de São Paulo, fundada pelo pai em 1967, aos 14 anos. Aproveitou o período de férias escolares para "brincar de escritório". Atualmente, cuida da área administrativa e financeira de uma das maiores distribuidoras de cervejas e refrigerantes do país (RAMIRO, VOCÊ S/A, edição 152, 2011, p. 42-44).
\end{abstract}

A figura dessa executiva "poderosa" não é construída somente por meio dos resultados obtidos pela sua maneira de pensar e/ou ser profissional executiva, mas também por meio da sua maneira de ser "mulher feminina": "o que chama atenção nesse núcleo feminino [...] é o modelo de gestão, focado na valorização de pessoas e resultados duradouros e ascendentes"; e pela sua capacidade heroica de concilar tudo: "além disso, essas cinco mulheres têm muito em comum: estão na casa dos 40 anos, possuem formação acadêmica consistente, fazem atividades físicas com muita disciplina e prazer e, é claro, são profissinais extremamente dedicadas ao trabalho" (RAMIRO, VOCÊ S/A, edição 152, 2011, p. 44).

Desse modo, cada um desses atores tem sua narrativa organizada em dois ou três parágrafos, antes dos quais é apresentada uma pequena imagem que simula uma tampinha de garrafa. Abaixo da primeira tampinha, a história apresentada é de Graziela Soleira. Tal qual nas matérias já abordadas, o enunciador constrói o percurso de empoderamento do ator destacando a conciliação dos papéis: "Ao ver todo o empenho de Graziela na companhia, é de se imaginar que a família fique em segundo plano. Nada disso. 'Sou supermãe, a família é minha prioridade', diz” (RAMIRO, VOCÊ S/A, edição 152, 2011, p. 44). Além da conciliação de papéis, o enunciador destaca ainda a atenção que o ator tem com a sua vida pessoal: "Acredita que ainda sobre tempo para a academia? Sim, ela nada e faz musculação alternadamente todos os dias" (RAMIRO, VOCE $S / A$, edição 152, 2011, p. 44).

O mesmo se dá na narrativa do ator Adriana Neves, em que o enunciador valoriza o modelo de gestão com foco nas pessoas: “'Gosto de treinar pessoas, lidar com gente', diz ela”; e destaca a conciliação de papéis: "Doze dias após o parto do filho Henrique, hoje com 12 anos, ela já estava de volta ao escritório. Nem por isso deixou de cumprir as obrigações de mãe - 
amamentou o filho durante seis meses" (RAMIRO, VOC $\hat{E} S / A$, edição 152, 2011, p. 45). Por último, o destaque é dado à atenção que o ator tem com a vida pessoal: "Adriana, de 42 anos, também arruma tempo para exercer seu lado atleta, quando se junta a seu grupo de ciclistas para treinar três vezes por semana e pedalar até 60 quilômetros nos fins de semana" (RAMIRO, VOCE $S / A$, edição 152,2011, p. 45).

A narrativa que configura o ator Maria Eugênia Pedroza também não é diferente: o enunciador destaca a capacidade de equilibrar firmeza e frieza com habilidade de ouvir; ressalta a conciliação de papéis e a valorização do lado pessoal da vida: "mãe de dois filhos, ela pratica kickboxing e faz caminhadas para relaxar" (RAMIRO, VOCÊ $S / A$, edição 152, 2011, p. 45). Cássia Abrantes, a "desbravadora da zona da mata pernambucana”, 45, contadora, também é uma executiva cuja narrativa "enche os olhos": "mora na praia de boa viagem, em Recife, com o marido Eduardo Abrantes, 55. Caminha três vezes por semana, faz pilates e massagem e vive rodeada de amigos" (RAMIRO, VOCÊ S/A, edição 152, 2011, p. 45-46). Entretanto, o enunciador anuncia que "nada veio de graça" e revela o preconceito sofrido pelo ator: "[...] 'quando viemos para cá, os comerciantes só dirigiam a palavra ao meu marido', lembra Cássia” (RAMIRO, VOCÊ S/A, edição 152, 2011, p. 45).

A última narrativa é do ator Mariela Baptista, narrativa que, tal como as outras, destaca o equilíbrio entre valores aparentemente contraditórios: “"Gosto de gente, não desisto das pessoas', diz. Mas ela é exigente. 'Sou firme e justa"” (RAMIRO, VOCÊ S/A, edição 152, 2011, p. 46). Uma vez mais, a conciliação entre os vários papéis e entre o lado profissional e pessoal da vida é valorizado pelo enunciador:

Casada há 17 anos, Mariela é mãe de dois filhos. "Para equilibrar o lado pessoal e profissional, ensinei meus filhos a valorizar a qualidade do tempo", diz. Além da família e do trabalho, Mariela arruma tempo para fazer academia três vezes por semana e assumir o ofício de catequista numa igreja da cidade. Como ninguém é de ferro, para relaxar, Mariela gosta de sair para dançar (RAMIRO, VOCE S/A, edição 152, 2011, p. 46).

Dessa matéria depreende-se, pois, um enunciador preocupado em mostrar que o /poder/, ou melhor, a /nobreza/ ${ }^{6}$ dessas mulheres de destaque consiste na superação, na conciliação de todos os papéis, na elevação de espírito que faz com que elas sejam desbravadoras e, logo em seguida, maternais. Nada é dito acerca da realidade diária do trabalho executado por elas, nada é dito sobre a realidade da Ambev, conhecida como uma empresa de DNA masculino ${ }^{7}$; apenas se fala sobre a multiplicidade de papéis desempenhados por essas mulheres, e que é um dos principais motivos pelos quais elas se tornam dignas de uma matéria de peso dentro da revista $V O C E \hat{E} S / A$.

É, portanto, o velho estereótipo da incompatibilidade entre o sucesso/poder e a feminilidade que é quebrado pelo enunciador do periódico. E é quebrado para justificar a presença e a permanência desses atores no cenário corporativo. Se antes, no passado, ou ainda hoje, em 
início de carreira, a mulher tem de se masculinizar e portar um comportamento austero/rígido, padronizando assim seu comportamento com o que parece ser o comportamento masculino nas grandes corporações, ela pode, logo depois, e a cada vez mais, assumir sua feminilidade, sua leveza/maleabilidade, doçura, e tantos outros adjetivos que também remontam ao papel de /mãe/, /esposa/ e /mulher/.

\section{CONSIDERAÇÕES FINAIS}

A concepção do poder feminino não sofreu tantas transformações ao longo dos anos de publicação da revista. A primeira matéria analisada, "Mulheres no poder", por exemplo, revelou um enunciador bastante preocupado em alertar seu enunciatário sobre a importância de ser uma executiva bem-sucedida, poderosa e, ao mesmo tempo, preservar um relacionamento saudável em casa, por meio do comportamento "cerimonioso" e do exercício de um "egoísmo saudável". Imperativos como "A dois é melhor", "Faça cerimônia", "Admire o parceiro", que identificam enunciados-conselhos nessa reportagem, são a confirmação de que, por trás de um discurso de padronização do modo de pensar e/ou ser ou mesmo portar-se e/ou parecer de homens e mulheres em posição executiva, havia, de fato, uma preocupação em persuadir o enunciatário de que uma executiva poderosa precisa, para concretizar seu percurso de empoderamento, ter ao lado um parceiro e, logo, constituir família. A segunda e a terceira matérias revelam um enunciador que também busca persuadir seu enunciatário sobre o mesmo ponto, embora não apresentem enunciados-conselhos explícitos nem usem imperativos. São narrativas-depoimentos que permitem ao enunciatário, por meio da disposição desses pequenos textos em determinada sequência, reconstruir um percurso no qual há uma variação de comportamentos e atitudes a serem adotados. Embora pouco seja dito sobre o comportamento dessas mulheres no ambiente doméstico, é evidente que a família atua como uma espécie de "mola propulsora" na consolidação da carreira corporativa.

Se a padronização homem/mulher aparece, é apenas num primeiro momento do percurso do ator, momento em que ele tem que provar que é competente para fazer e ser uma executiva de sucesso. Logo depois, essa padronização é neutralizada e a mulher busca destacar-se de uma maneira menos agressiva e menos ambiciosa, momento propício para a valorização de uma forma de vida equilibrada ou moderada, lembrando a tão aclamada capacidade feminina de conciliar tudo, inclusive os opostos, como garantem os títulos e subtítulos das seções e as próprias atividades elencadas pelos atores, que vão de kickboxing e academia aos cuidados com a horta e à catequese, passando pelo cuidado dos filhos: trabalho, família, corpo e espírito valorizados. Desejosos de notoriedade, esses atores são sujeitos apaixonados pelo poder "ameno", que prezam 
as relações interpessoais e a manutenção dos laços emocionais, remetendo a um estilo pluridimensional de vida. Têm-se então, por fim, o que Lipovestky já anunciava acerca da terceira mulher, que irrompe após séculos de dominação masculina: ela é já outra, embora ainda a mesma doce, martenal e feminina mulher. É essa forma de vida feminina que o periódico em questão e a mídia brasileira em geral configura: uma forma de vida marcada por estrondosas rupturas, mas também por grandes e silenciosas permanências, que prometem não libertar a mulher tão cedo do velho mito do Eterno Feminino.

\section{NOTAS}

$1 \mathrm{O}$ termo empoderamento é um neologismo que se refere maioritariamente ao aumento da força política, social ou econômica de grupos alvos de discriminação (étnica, religiosa, sexual ou outra). Disponível em: $<<$ http://www.flip.pt/Duvidas-Linguisticas/Duvida-Linguistica/DID/1175 >> Acesso em: 10 fev. 2016.

2 A classificação dos tipos em serifados e não-serifados é o principal sistema de diferenciação de letras. A esse respeito, acredita-se que os serifados tenham surgido no Renascimento como uma alternativa às letras góticas, de modo a criar composições mais leves. As serifas (pequenos prolongamentos que dão acabamento no final das hastes de certas letras) tendem a guiar o olhar através do texto, favorecendo uma leitura contínua, visto que as letras serifadas parecem juntar-se devido aos seus prolongamentos, unindo as palavras, em bloco. Por outro lado, os tipos sem serifa valorizam cada palavra individualmente e tendem a ter maior peso e presença aos olhos. Disponível em: $<<$ http://pt.wikipedia.org/wiki/Serifa $>>;<<$ http://www.printi.com.br/blog/aprenda-mais-sobre-tipograf ia-serifas-infografico $>>;<<$ http://ricardoartur.com.br/1001/files/2011/06/Relatorio-novo-editado.pdf $>$ >. Acesso em: 10 fev. 2016.

3 Mostrar a sola dos sapatos a alguém não tem a mesma conotação em todas as culturas. José Augusto Wanderley, autor de "Negociação total" (1998), relata o caso de uma negociação entre brasileiros e árabes: "as negociações corriam de forma extremamente favorável e nada fazia antever a menor probabilidade de insucesso. Acidentalmente, um dos representantes brasileiros cruzou as pernas e a sola do seu sapato ficou apontada na direção do principal negociador árabe. A reação deste foi surpreendente: levantou-se e deu a negociação por encerrada. [...] É que, naquela região, mostrar a sola do sapato era sinal de profundo desrespeito". Disponível em: $<<$ http://www.jawanderley.pro.br/ artigo24.html >>. Acesso em: 10 fev. 2016.

4 Matéria não assinada. Ao citá-la, colocaremos apenas nome da revista, número da edição, ano e página.

5 Segundo Henrique Malzone, a Franklin Gothic foi um estrondoso sucesso desde seu lançamento: seu êxito resulta da bonita e delicada relação peso-clareza, e se deve ao fato de, ao contrário de outras fontes Bold, ter finesse e elegância. Disponível em: $<<\mathrm{http}$ ://www.professionalpublish.com.br/?id=77,1,view, 2,14257,sid >>. Acesso em: 10 fev. 2016.

6 Seria interessante pensar que a nobreza é o oposto da vulgaridade e refletir a respeito da escolha do lexema "rainhas" para o título dessa reportagem que aborda a carreira - e a vida - das executivas da Ambev. Impossível não associar o principal produto da empresa, a cerveja, ao estereótipo da vulgaridade, da libertinagem e depreender um enunciador que quer romper com esse estereótipo, mostrando mulheres dedicadas ao trabalho, à família, ao corpo e também ao espírito.

7 Outras reportagens de VOCÊ S/A abordam o universo da Ambev como marcado pela dureza/frieza, um lugar onde se exigem decisões rápidas, onde se faz mais do que se discute, onde se priorizam os resultados. 


\section{REFERÊNCIAS}

ABRIATA, Vera Lucia Rodella; NASCIMENTO, Edna Maria Fernandes Santos (orgs.). Formas de vida da mulher brasileira. Ribeirão Preto/SP: Editora Coruja, 2012.

BASSO-FOSSALI, Pierluigi. Possibilisation, disproportion, interpénétration: trois perspectives pour enquêter sur la productivité de la notion de forme de vie en sémiotique. Nouveaux Actes Sémiotiques [en lignte]. NAS: Limoges, 2012b, n. 15. Disponível em: $<<$ http://revues.unilim.fr/ nas/docannexe.php?id=4219>>. Acesso: 21 jan. 2016.

BUARQUE, Chico; PONTES, Paulo. Gota d'água. Rio de Janeiro: Civilização Brasileira, 1976.

FONTANILLE, Jacques. Présentation. Recherches Sémiotiques. Semiotic Inquiry [R.S.S.I.], Montreal, n.13, p. 5-12, 1993.

.; LOMBARDO, Patrizia; RALLO-DITCHE, Elisabeth. Dictionnaire des passions littéraire. França: Berlin, 2005.

Formes de vie. Liège: PUL, “Colection Sigilla”, 2015.

La sémiotique face aux grands défis sociétaux du XXIe siècle. Nouveaux Actes Sémiotiques [en ligne]. NAS: Limoges, 2015, n. 18. Disponível em: $<<$ http://epublications.unilim.fr/revues/ as/5320>>. Acesso em: 10 fev. 2016.

GAROTAS SUPERPODEROSAS. Dinheiro: Perfil. VOCÊ S/A, edição n ${ }^{\circ}$ 130, p. 80-85, abr. 2009.

GREIMAS, Algirdas Julien. Le beau geste. Recherches Sémiotiques. Semiotic Inquiry [R.S.S.I.], Montreal, n.13, p.21-35, 1993.

.; COURTÉS, Joseph. Dicionário de Semiótica. São Paulo: Contexto, 2. ed., 2013.

HOUAISS, Antônio; VILLAR, Mauro Salles. Dicionário Houaiss da Língua Portuguesa [em CD-ROM]. Rio de Janeiro: Objetiva, 2001.

LANDOWSKI, Eric. Formes de l'alterité et styles de vie. Recherches Sémiotiques. Semiotic Inquiry [R.S.S.I.], Montreal, n.13, p.69-93, 1993.

Presenças do outro: ensaios de sociossemiótica II. Tradução de Mary A. L. de Barros. São Paulo: Perspectiva, 2002.

LYPOVETSKY, Gilles. A terceira mulher: permanência e revolução do feminino. Tradução de Maria Lucia Machado. São Paulo: Companhia das Letras, 2007.

NASCIMENTO, Edna Maria Fernandes Santos. Estados de alma e formas de vida da mulher. In: MARCHEZAN, Renata Coelho; CORTINA, Arnaldo; BAQUIÃO, Rubens César (orgs.). A abordagem dos afetos na semiótica. São Carlos/SP: Pedro \& João Editores, 2011, p. 119-147.

.; ABRIATA, Vera Lucia Rodella (orgs). Formas de vida: rotina e acontecimento. Ribeirão Preto/SP: Editora Coruja, 2014. 
PORTELA, Jean Cristtus; SCHWARTZMANN, Matheus Nogueira. Rê Bordosa: forma de vida e moralização. In: ABRIATA, Vera Lucia Rodella; NASCIMENTO, Edna Maria Fernandes Santos (orgs.) Formas de vida da mulher brasileira. Ribeirão Preto/SP: Editora Coruja, 2012, p. 113-136.

RAMIRO, Denise. As Rainhas da Ambev. Mercado: Mulheres. VOCÊE S/A, edição $n^{\circ} 152, p$. 42-46, fev. 2011.

ROCHA, Márcia. Mulheres no poder. VOCÊ S/A, edição no 47, p. 38-48, mai. 2002.

WITTGENSTEIN, Ludwig. Investigações filosóficas. Trad. José Carlos Bruni. São Paulo: Nova Cultural, 1999.

ZILBERBERG, Claude. El jardín como forma de vida. In: Semiótica tensiva y formas de vida. Puebla: Dirección General de Fomento Editorial, 1999. 